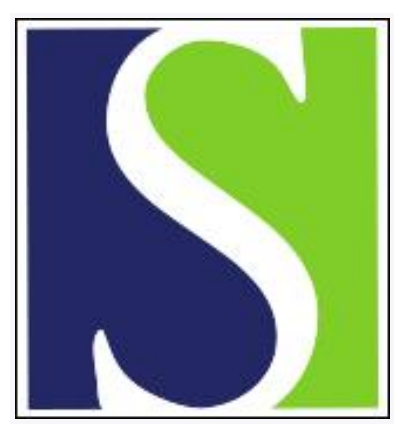

Scand J Work Environ Health 1979;5(4):352-361

https://doi.org/10.5271/sjweh.2646

Issue date: Dec 1979

The effects of moderate heat stress on mental performance.

by Wyon DP, Andersen I, Lundqvist GR

Key terms: arousal; chamber; climate; heat stress; memory; mental performance; moderate heat stress; school work; temperature swing; thermal comfort

This article in PubMed: www.ncbi.nlm.nih.gov/pubmed/538426

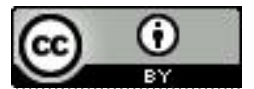




\title{
The effects of moderate heat stress on mental performance
}

by DAVID P. WYON, Ph.D., IB ANDERSEN, M.D., and

GUNNAR R. LUNDQVIST, M.Sc. ${ }^{1}$

\begin{abstract}
WYON, D. P., ANDERSEN, I, and LUNDQVIST, G. R. The effects of moderate heat stress on mental performance. Scand. $j$. work environ. \& health 5 (1979) $352-361$. Moderate heat stress is believed to affect mental performance by lowering levels of arousal. Conscious effort can counteract this effect. In most experiments, raised temperatures are perceived at the start by subjects and can act as a stimulus to exert conscious effort. In practice, temperatures usually rise slowly and may therefore have a more marked effect. Thirty-six male and 36 female 17-year-old subjects in standard cotton uniforms $(0.7 \mathrm{clo})$ were exposed in groups of four in a climate chamber to rising air-temperature conditions typical of occupied classrooms, in the range $20-29^{\circ} \mathrm{C}$. The maximum rate of rise was $4^{\circ} \mathrm{C} / \mathrm{h}$. Each group performed mental work during three successive periods of 50 min with 10 -min breaks between. During each break the air temperature was reduced by $3^{\circ} \mathrm{C}$. Sentence comprehension was significantly reduced by intermediate levels of heat stress in the third hour. A multiplication task was performed significantly more slowly in the heat by male subjects, showing a minimum at $28^{\circ} \mathrm{C}$. Recognition memory showed a maximum at $26^{\circ} \mathrm{C}$, decreasing significantly at temperatures below and above, and an independent measure of degree of certainty in recall showed a maximum at $27^{\circ} \mathrm{C}$. These findings are in accordance with the hypothesis of reduced arousal in moderate heat stress in the absence of conscious effort.
\end{abstract}

Key words: arousal, climate chamber, heat stress, memory, mental performance, school work, temperature swings, thermal comfort.

It has been suggested $(12,13)$ that the effect of moderate heat stress is to lower levels of arousal, while higher levels of heat stress tend to raise arousal. The effect is believed to be a largely unconscious, adaptive behavioral response. As thermal stress rises beyond the range in which vasodilatory control of heat balance is effective, sweating must progressively increase and take control of heat balance.

1 Institute of Hygiene, University of Aarhus, Universitetsparken, Århus, Denmark.

Reprint requests to Dr. D.P. Wyon, National Swedish Institute for Building Research, Box 785, S-801 29 Gävle, Sweden.
However, as the onset of sweating takes time and tends to be disliked by clothed, sedentary workers, the immediate conscious or unconscious response is to relax as much as possible, bodily heat production thus being immediately reduced and the onset of sweating perhaps postponed. This suggests that moderate heat stress affects the performance of mental work by reducing arousal to a minimum just before sweating becomes effective as a means of thermoregulation.

Subjects comfortable at $27^{\circ} \mathrm{C}$ have reported that they exert the least effort at that temperature when performing mental work (10), and marked effects on perfor- 
mance have in fact been demonstrated (8, $10,17)$. Where performance was maintained, it has been shown to be at the cost of increased effort (16). These experiments were carried out under constant temperature conditions. Subjects were thus able to perceive the need for increased effort to maintain performance not only by means of their sensations during the exposure, but also by experiencing the contrast between external and exposure conditions as they entered the exposure chamber. The present experiment was designed to investigate the effects of moderate heat stress on the performance of school work, under conditions in which the latter stimulus to compensatory effort was removed by exposing subjects to slowly rising temperatures. The temperature-time profile was chosen to be typical of conditions in a room occupied by a number of people on a hot day, the temperature rising by $3-4^{\circ} \mathrm{C}$ in the course of an hour before being reduced temporarily, as if by flush ventilation or by a short break in which the room was unoccupied. A variety of mental tasks, chosen for their relevance to various aspects of school work, was used to investigate the nature of moderate heat stress effects on mental performance in more detail.

\section{METHODS}

\section{Experimental conditions}

The experimental conditions and an analysis of the thermal comfort sensation of the subjects have been reported elsewhere (18). The subjects were 72 healthy Danish high-school pupils of high ability, 36 males and 36 females; they were volunteers, but paid by the hour. Each subject participated only once. None of them were heat-acclimatized. They were randomly assigned in single sex groups of four to one of the three temperature conditions, shown in the lower part of fig. 1. The control condition (0) was a saw-tooth variation of temperature rising from 20 to $23^{\circ} \mathrm{C}$ in the course of 50 min, then decreasing to $20^{\circ} \mathrm{C}$ in the following $10-\mathrm{min}$ break, for three identical cycles. In condition 1 a base-line increase of $1^{\circ} \mathrm{C} / \mathrm{h}$ was imposed on the saw-tooth variation of condition 0 , with the result that the temperature rose $4^{\circ} \mathrm{C}$ in $50 \mathrm{~min}$ and fell $3^{\circ} \mathrm{C}$ in the break, starting as for condition 0 at $20^{\circ} \mathrm{C}$ and thus ending at $26^{\circ} \mathrm{C}$ after $3 \mathrm{~h}$. In condition 2 the same variation occurred but at a higher level; the temperature was initially $23^{\circ} \mathrm{C}$ and thus increased to $29^{\circ} \mathrm{C}$ in $3 \mathrm{~h}$. The temperature was measured as the arithmetic mean of the air and radiation temperature and will be referred to as temperature only. The climate chamber (3) was designed for dynamic studies, and the walls inside the insulation had a very low thermal capacity. The absolute humidity of the air was constant at $9 \mathrm{~mm} \mathrm{Hg}$ (corresponding to a relative humidity of $50 \%$ at $20^{\circ} \mathrm{C}$ ), the air velocity was $0.12 \pm 0.03 \mathrm{~m} / \mathrm{s}$, and the air supply rate was $600 \mathrm{~m}^{3} / \mathrm{h}$ (13 air changes per hour) with no recirculation.
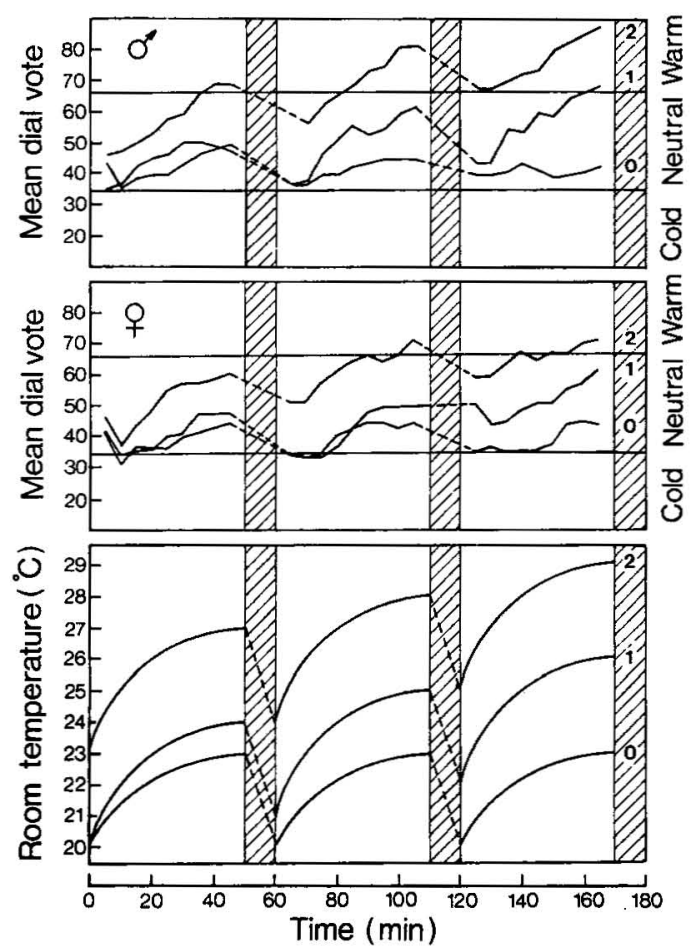

Fig. 1. The two upper sets of curves show the variation with time of the mean dial vote. The lower set of curves show the variation with time of ambient temperature during the three experimental conditions 0,1 and 2 . The hatched columns represent the rest periods. 
The subjects wore standard cotton drill suits. Cotton shorts and a cotton T-shirt were worn underneath, together with cotton socks and light canvas shoes. The total insulation value of this ensemble was 0.7 clo. The exposures took place after lunch each day after a normal morning at school.

\section{Performance tests}

Three different test assemblies were used, each taking $50 \mathrm{~min}$. Each group of four subjects encountered all three test assemblies in the course of their 3-h exposure. The six possible orders of presentation were replicated three times in a balanced Latin-square design so that each test assembly was performed by eight different subjects in each hour of the three temperature conditions, i.e., by one male and one female group. Independent measure comparisons were therefore possible for each performance test for sex, time, and temperature condition.

Sentence comprehension. A translated version of a test of grammatical reasoning (4) was used. The subjects worked through a typical list of statements, marking them as true or false. The statements were of the following types:

\section{A follows $\mathrm{B}$ : $\mathrm{BA}$ \\ $B$ is not preceded by $A$ : $\quad A B$}

They were printed in a pseudorandom order with a rolling restriction on their recurrence. Subjects attempted as many as possible in $5 \mathrm{~min}$, and both speed and error frequency were recorded.

Multiplication. Each unit of the multiplication test consisted of two three-digit numbers, without zeros, printed one below the other, to be multiplied together. There was space below each unit to set out the calculation in the conventional way. Subjects attempted as many units as possible in $15 \mathrm{~min}$, and both speed and error frequency were recorded.

Word memory. A list of 25 common words, chosen at random from a much longer list, was presented visually to the subjects, who read each word aloud in unison with the experimenter. The list was removed, and the subjects then worked through a list of 50 common words including the 25 "target" words. The task was to classify each word as seen/unseen, and each answer as certain/uncertain. After an additional $20 \mathrm{~min}$, during which a reading task was performed, the same list of $\mathbf{5 0}$ words was again presented, arranged in a different random order; it was to be similarly classified.

Cue utilization. Subjects performed three parallel versions of the Tsai-Partington test (1) at intervals during one 50-min period. Twenty-five circles containing letters or numbers, placed at random on a page, must be linked with a line through 1-A-2-B- and so on. The score was taken as the number of correct links made in $\mathbf{4 0}$ s. The performance of this test is known to be adversely affected by a high level of motivation (6), and moderate heat stress has been shown (16) to improve performance of the test, probably by lowering arousal and motivation.

Other performance tests. Spelling ability was tested with a list of short sentences, each including one commonly misspelled test word. In half of the sentences the test word was incorrectly spelled. Vocabulary was tested with a list of word definitions, half of which were wrong. Each of the units was to be classified as correct/incorrect and each such answer as certain/uncertain. Spelling and vocabulary performance were then scored in the same way as the word memory test. A 15-min test of reading speed and comprehension was used, on which the subjects had to select the correct word from three alternatives at regularly occurring choicepoints in the text $(8,16)$. Two open-ended tests of creativity were used; the subjects had to list as many novel uses as possible for some familiar objects, and as many instances as possible of certain simple kinds of objects, e.g., red objects, square objects (16). Finally, a 15-min test of manual dexterity and perseverance was included; using an IBM "Port-a-Punch," subjects had to enter eight five-digit ran- 
dom numbers from a prepared list onto special computer punch cards later scored for speed and errors.

\section{RESULTS}

Comfort [resumé of a published analysis (18)]

Thermal comfort was recorded with the dial-voting technique. It may be seen from the average comfort-vote curves in the upper part of fig. 1 that the conditions were judged to be comfortable throughout, except that the male subjects became slightly too hot towards the end of the second and third hours of condition 2, i.e., at temperatures above $27^{\circ} \mathrm{C}$. The distribution of comfort votes about the mean was such that no more than $5 \%$ of the male subjects were too hot at $23^{\circ} \mathrm{C}$. It could be shown that the subjects were more often distracted by their thermal sensations when they were uncomfortable - they adjusted the voting dial more often. Twenty-eight percent of the female subjects were too cold at $23^{\circ} \mathrm{C}$, but in practice they would be able to wear more clothing. A temperature of $23^{\circ} \mathrm{C}$ was therefore recommended as a suitable maximum temperature for school classrooms on the basis of the comfort analysis, even under summer conditions.

\section{Skin temperature variation}

In fig. 2 the variation of mean skin temperature (10 points) with time is shown for the three temperature conditions. It may be seen that there was no appreciable hysteresis; the mean skin temperature was a closely linear function of temperature regardless of the time or foregoing temperature variation. In fig. 1 it is apparent that the comfort votes also followed temperature without hysteresis. In the following analysis of performance it is therefore assumed, unless a time effect is present in the control condition, that interactions between temperature condition and time may be interpreted as being due to the rising temperatures, i.e., that performance was also a direct but not necessarily linear function of the prevailing temperature at any given time.

\section{Performance analysis}

Data fulfilling the necessary assumptions were examined with an analysis of variance in a $3 \times 3 \times 2$ independent measures design with temperature condition, hour, and sex as the independent variables, respectively. F-values are stated when significant. A simpler nonparametric analysis was used instead when the data appeared not to be distributed normally, and also to confirm the influence of single variables when interactions were indicated by the analysis of variance.

Sentence comprehension. The analysis of variance indicated a significant effect of
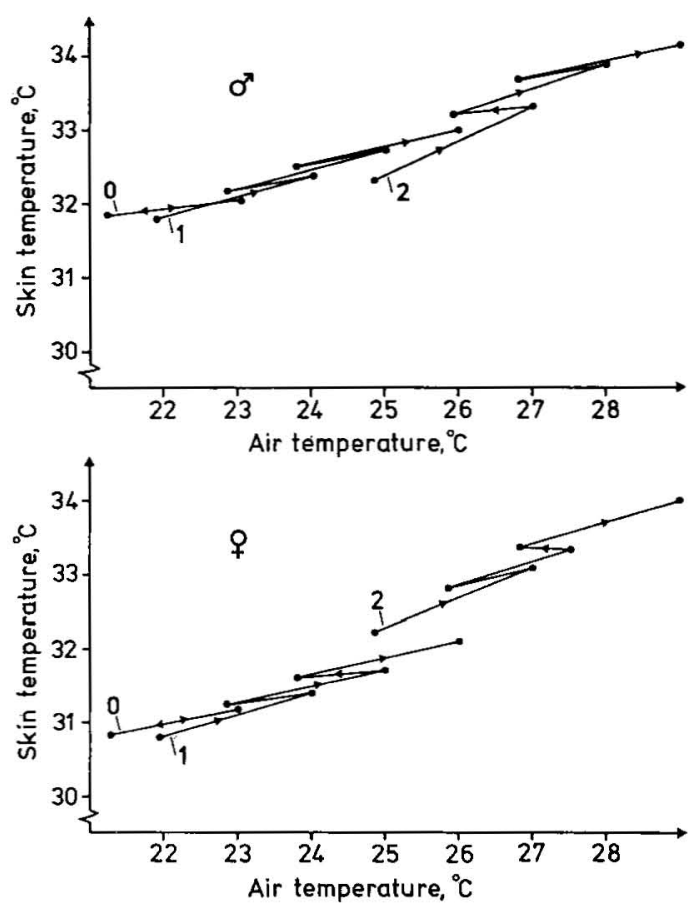

Fig. 2. Variation of the mean skin temperature with the ambient temperature. The points shown are the mean values at the start and end of each 50-min rising-temperature condition for the three experimental conditions 0 , 1 and 2. 
time $-\mathrm{F}(2,54)=3.70(\mathrm{P}<0.05)-$ and a significant interaction between temperature condition and time $-\mathrm{F}(4,54)=2.77$ $(\mathrm{P}<0.05)$. A Kruskal-Wallis analysis (14) for the effect of time in the control condition, male and female data pooled, yielded a chi-square of $4.061(0.10<\mathrm{P}<0.20)$ with two degrees of freedom. The trend, shown in the upper part of fig. 3 , is the usual tendency to work less hard at difficult or boring tasks in the middle period of an exposure. The effect of temperature must therefore be tested for each hour separately. A Kruskal-Wallis analysis for differences between temperature conditions yielded chi-square values of 2.029 (NS), 1.805 (NS) and 7.726 (P $<0.05$ ) with two degrees of freedom for the first, second and third hour, re-
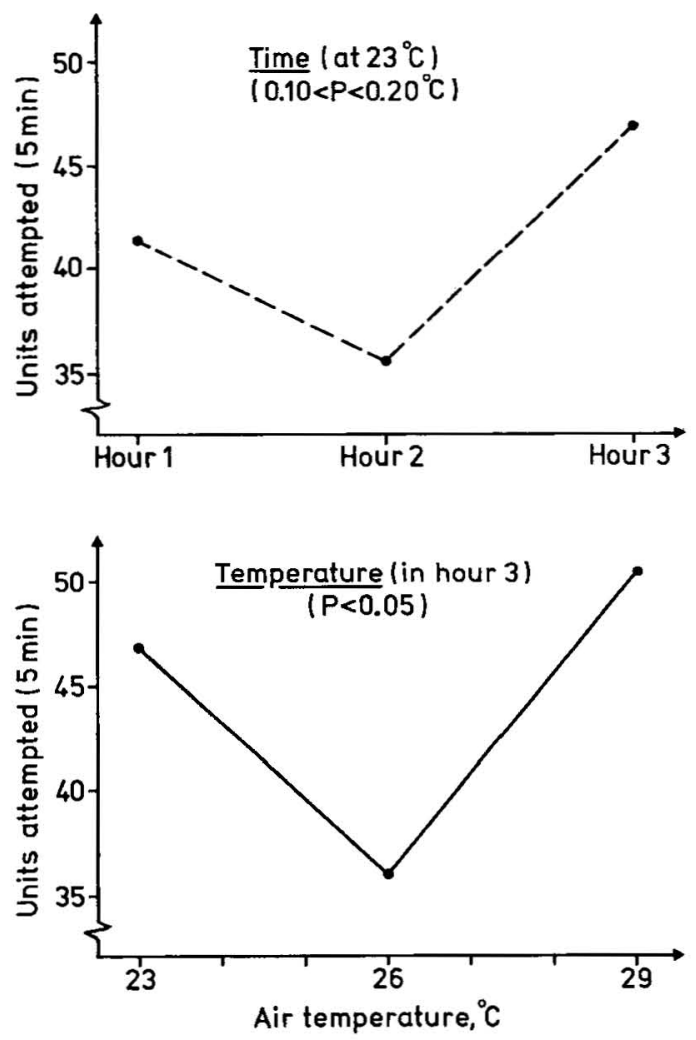

Fig. 3. Performance of the sentence comprehension test. The mean number of units attempted in $5 \mathrm{~min}$ is shown as a function of time at $23^{\circ} \mathrm{C}$ in the upper part of the figure and as a function of temperature in the third hour in the lower part. Each point represents the mean performance of eight different subjects. spectively. This test was performed between the 24th and 29th minute of the hour, by which time the temperature had risen to within $0.5^{\circ} \mathrm{C}$ of the final temperature for each hour (fig. 1). The comparisons were therefore between $23 / 24 / 27^{\circ} \mathrm{C}$ in the first hour, $23 / 25 / 28^{\circ} \mathrm{C}$ in the second hour and $23 / 26 / 29^{\circ} \mathrm{C}$ in the third hour. The significant third-hour effect is shown in the lower part of fig. 3. Subjects performed this test over $20 \%$ more slowly at the intermediate temperature of $26^{\circ} \mathrm{C}$. There were no significant effects on the error frequency, which averaged $5 \%$.

Multiplication. The analysis of variance indicated a significant interaction between temperature condition and sex - F $(2,54)$ $=3.24(\mathrm{P}<0.05)$ for the multiplication test. A repetition of the analysis for each sex separately indicated a significant effect of temperature condition for the male subjects - F $(2,27)=4.37$ $(\mathrm{P}<0.05)$ - but no significant effect for the female subjects. This test was performed between minutes 32 and 47 of the hour. The male subjects worked more slowly in condition 2. In fig. 4 the scores are shown for each sex as a function of the average final temperature in conditions 0 and 1 , but as a function of the temperature experienced by each subgroup in condition 2 to show in more detail the trends around the critical temperature. A Kruskal-Wallis analysis of this grouping, with cell frequencies of $12,12,4,4$ and 4 , yielded a chi-square of 10.605 for the male subjects $(\mathrm{P}<0.05)$ and 3.644 for the female subjects (NS) with four degrees of freedom. The test was performed the most slowly by the male subjects at $28^{\circ} \mathrm{C}$.

There were no significant effects on the error frequency, which averaged $23 \%$.

Word memory. The rating scale replies were used to construct the ROC (Receiver Operating Characteristic) curve of signal detection theory (7) for each subject, on the analogy that recognition memory involves the detection of a "signal" (memory trace) in noise.

[The ordinate is taken to be the probability of the subject correctly recognizing any given word, and the abscissa is taken to be the probability of false-positive recognition, i.e., 
that he will incorrectly "recognize" the word. Both can take any value between 0 and 1 , depending on the subject's ability to remember words and his willingness to risk saying he does in error. These two aspects of the subject's performance can vary independently; with a given ability to remember, the subject can appear to recognize more words correctly by saying he does more often, i.e., by increasing the probability of false-positive recognition commensurately. The relationship between the two probabilities defines the ROC curve. A straight diagonal through the origin represents straightforward guesswork. If subjects had no memory of the list, they would achieve, on the average, as many false-positive recognitions as correct recognitions, regardless of how certain they said they were of their replies on the rating scale. The cumulative frequency of correct and false-positive recognitions for each category of the rating scale defines three points on the ROC curve, which must also pass through the origin and the top right-hand corner. The area under the ROC curve thus defined by five points can be calculated and is a nonparametric, dimensionless measure of recognition memory performance regardless of criterion. The slope of the tangent at the point defined by the center of the rating scale can also be estimated; it is a measure of the criterion used by the subject. In signal detection theory it is called the likelihood ratio "beta." The value of beta increases if the subject is reluctant to make false-positive recognitions, i.e., it is a measure of his degree of caution in recall. In the present case beta was taken to be the slope of the line joining the first and third points defined by the rating scale reply frequencies. Where subjects did not use all categories of the rating scale, no value of beta was derived. However, since the approximate locus of the ROC curve can be determined from a single point, the area under the curve was obtained in every case.]

Having read the target list $20 \mathrm{~min}$ from the start of the hour, the subjects attempted to remember the words twice, between minutes 22 and 27 and between minutes 43 and 48. The ROC curve analysis was carried out for each occasion separately, but the trends were found to be the same, and the final analysis was performed, for each subject, on the average of the values obtained on the two occasions.

Memory. The analysis of variance indicated a significant interaction between temperature condition and time - F $(4,54)=2.81(\mathrm{P}<0.05)$ for the memory test. No significant effects of time or sex could be shown under control condition 0 , but, with rising temperature conditions 1 and 2 taken together, there were significant interactions between temperature condition and time - F $(2,36)$
$=4.53(\mathrm{P}<0.05)$ - and between temperature condition and sex $-\mathrm{F}(1,36)=4.98$ $(\mathrm{P}<0.05)$. The trends with temperature for each sex are shown in fig. 5. Memory performance increased with rising temperatures up to a maximum at $26^{\circ} \mathrm{C}$, the reduction at temperatures above $26^{\circ} \mathrm{C}$ occurring only for the male subjects. The increase from 24 to $26^{\circ} \mathrm{C}$ can be shown to be significant; a Kruskal-Wallis analysis, pooling male and female data, yielded a chi-square of 6.041 ( $\mathrm{P}<0.05$ ) with two degrees of freedom. In the same way, the changes taking place between 26 and $29^{\circ} \mathrm{C}$ yielded a chi-square of $5.135 \quad(0.10<\mathrm{P}$ $<0.20)$ with three degrees of freedom.

Criterion. Nine of the 72 subjects did not use all four reply categories on the rating scale, so no beta value could be calculated for them. The analysis of variance, carried out with the unweighted cell means and a within-cell mean square with reduced degrees of freedom as recommended for missing data by Winer (15), indicated a significant interaction between temperature condition and time - F $(4,45)$

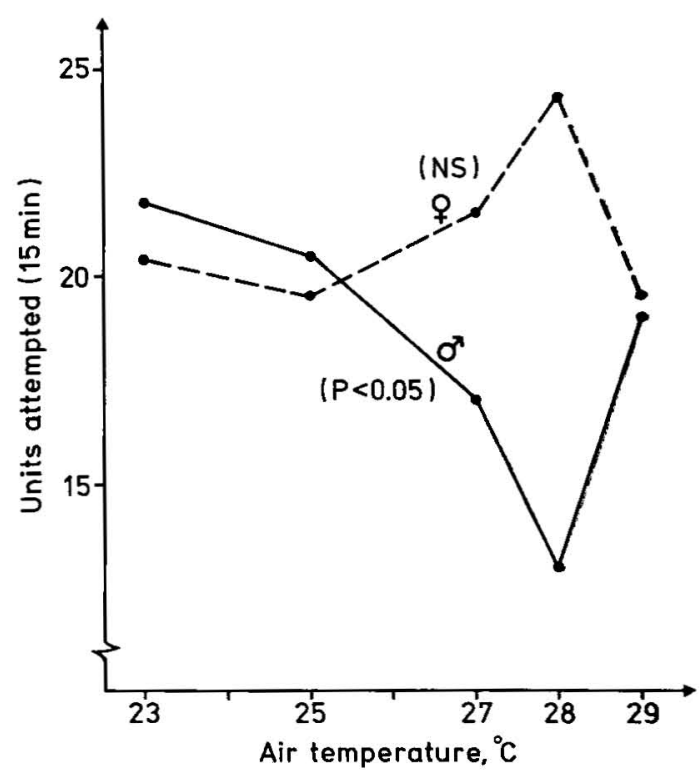

Fig. 4. Performance of the multiplication test by male and female subjects as a function of temperature. Each point represents the mean number of units attempted in $15 \mathrm{~min}$ by 12 , $12,4,4$ and 4 different subjects, respectively, from left to right. 


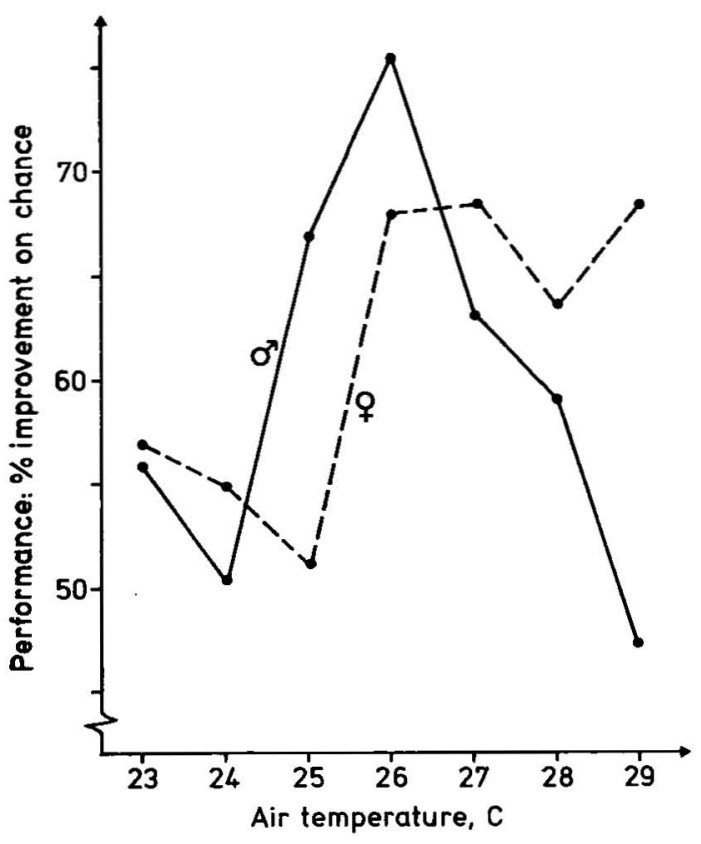

Fig. 5. Performance of the word memory test: recall as a function of temperature for male and female subjects. Each point represents the mean of four different subjects, except at $23^{\circ} \mathrm{C}$, at which temperature 12 subjects of each sex performed the test. All subjects performed the test twice. Performance is shown as the percentage improvement on chance performance 0.5 so that $50 \%$ represents an ROC curve area of 0.75 .

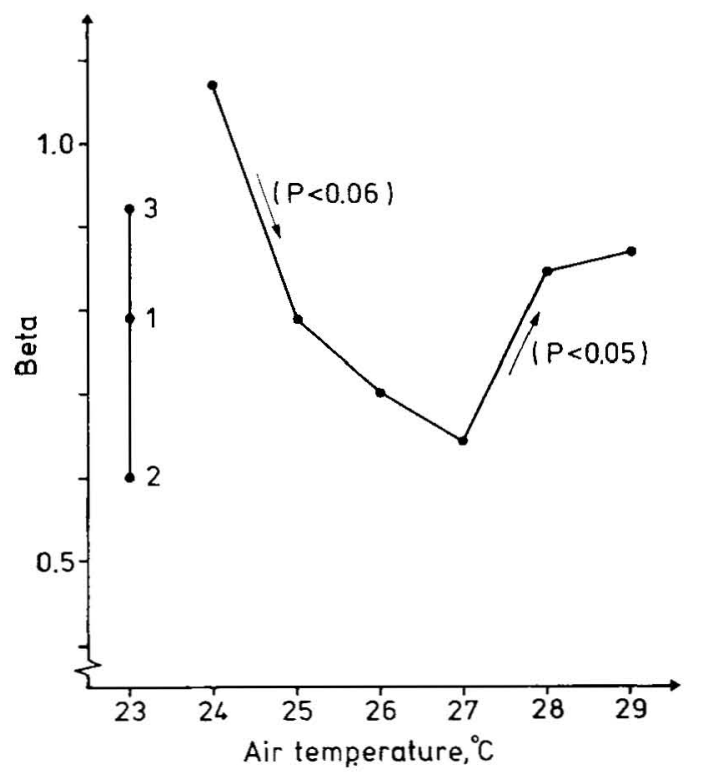

Fig. 6. Performance of the word memory test: degree of caution in recall, beta, as a function of temperature. Hour number is indicated for control condition 0 at $23^{\circ} \mathrm{C}$.
$=3.19(\mathrm{P}<0.05)$. There were no significant effects of time or sex under the control condition, but, with rising temperature conditions 1 and 2 taken together, the interaction between temperature condition and time was even more significant - F $(2,34)=6.15(\mathrm{P}<0.01)$. The trends with temperature are shown in fig. 6 . The beta value decreased to a minimum at $27^{\circ} \mathrm{C}$. The decrease from 24 to $27^{\circ} \mathrm{C}$ approached significance, the Kruskal-Wallis analysis, pooling male and female data, yielding a chi-square of $7.561 \quad(\mathrm{P}<0.06)$ with three degrees of freedom. The subsequent increase of beta from 27 to $29^{\circ} \mathrm{C}$ can be shown to be significant, the KruskalWallis analysis yielding a chi-square of $6.157(\mathrm{P}<0.05)$ with two degrees of freedom. The subjects were the most confident of their replies at $27^{\circ} \mathrm{C}$; they were less confident and took more care to avoid incorrect recognition at temperatures both above and below $27^{\circ} \mathrm{C}$.

Cue utilization. The first version of the Tsai-Partington test was performed in the first $5 \mathrm{~min}$ of the hour, before the temperature had effectively risen from its initial value. An analysis of variance indicated a significant main effect of temperature condition - F $(2,54)=3.82(\mathrm{P}<0.05)-$ and a significant interaction between temperature condition and time $-F(4,54)$ $=2.91(\mathrm{P}<0.05)$. The trends with temperature are shown in fig. 7. The performance of this test in the range 20 to $25^{\circ} \mathrm{C}$ shows a clear minimum at $23^{\circ} \mathrm{C}$.

The performance of the second and third parallel versions of this test showed marked learning and either very complex patterns of interaction, mainly between time and sex, or no significant effect at all. The results cannot be interpreted unequivocally in terms of temperature.

Other performance tests. No significant effects could be shown on the remaining performance tests, except that the female subjects performed the spelling test significantly better than did the male subjects $(P<0.05)$. The spelling, vocabulary, cardpunching, and first creativity test were carried out in the first $20 \mathrm{~min}$ of the hour, before temperatures had risen fully, but 
the reading test and the second creativity test were both carried out after the 30th minute of the hour, when temperatures had more closely approached their final values.

\section{DISCUSSION}

The results of our study indicate that the effects of moderate heat stress on mental performance are marked but by no means straightforward even when comfort sensation and skin temperature vary as closely linear functions of the prevailing temperature. An orderly relationship between heat stress and mental performance is postulated in the following interpretation of the observed results in terms of thermal effects upon arousal.

Performance of the sentence comprehension test demands concentration and clear thinking. It has recently been reported that a card-sorting version of this test was performed more slowly by hospital doctors with a sleep-debt of only $3 \mathrm{~h}$ (11). Performance of this test in the third hour of the present experiment was reliably worse at $26^{\circ}$ than at 23 or $29^{\circ} \mathrm{C}$. This result corresponds to the decline in the reading speed and comprehension of children found at $27^{\circ} \mathrm{C}$, in comparison with 20 and $30^{\circ} \mathrm{C}$ (8). Then, as now, the effect could be interpreted as a lowering of arousal at levels of moderate heat stress corresponding to the limit of vasodilatory control, just below the onset of sweating.

The multiplication task also demands concentration but is very well practiced and familiar. The male subjects performed least well at $28^{\circ} \mathrm{C}$, but the female subjects were unaffected. This difference may reflect the distracting effect of thermal discomfort, as the female subjects were not nearly so uncomfortable. The classroom behavior of 8-year-old boys has been shown to be affected more adversely by a room temperature of $27^{\circ}$ than by one of 20 or $30^{\circ} \mathrm{C}$. Girls were not affected in the same way by the intermediate temperature (20).

Recognition memory was improved by moderate heat stress. The male subjects remembered the words better at $26^{\circ} \mathrm{C}$ than at temperatures below or above this value. They were (justifiably) more confident of their answers at this intermediate temperature. The same test has been used to show that subjects were significantly more confident of their replies (i.e., beta took lower values) at a temperature $4^{\circ} \mathrm{C}$ above their individual optimum temperature (9). The comparison was between an average optimum temperature of $22.6^{\circ}$ and the raised temperature of $26.5^{\circ} \mathrm{C}$. In this case, confidence was misplaced, as recognition memory had not improved. This result suggests that the effect is an independent consequence of moderate heat stress. Analogously, subjects became less critical of their own replies in a creativity test at $27^{\circ} \mathrm{C}$ in comparison with 20 or $23.5^{\circ} \mathrm{C}$ (16). Raised arousal is believed to reduce cue utilization (5) and can therefore be expected to impair memory. The converse, that lowered arousal improves memory, is consistent with the arousal interpretation of the present results. The effect was quite large; the male subjects improved their

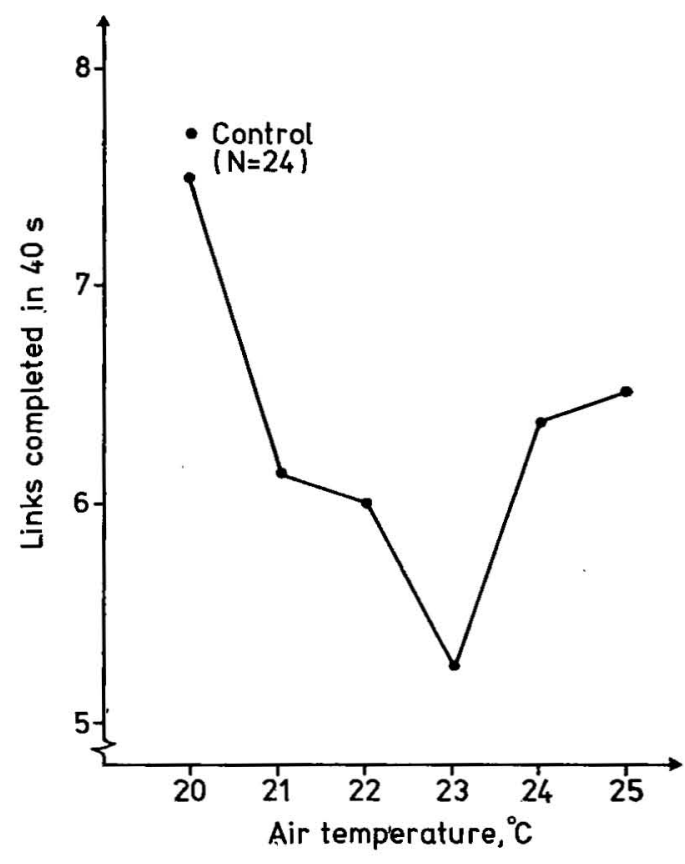

Fig. 7. Performance of the cue utilization test as a function of temperature. Each point represents the mean of eight different subjects tested at each temperature, except that $24 \mathrm{sub}$ jects were tested at $20^{\circ} \mathrm{C}$ in the control condition. 
ROC curve area from about 0.75 at 24 and $29^{\circ} \mathrm{C}$ (which is only $50 \%$ better than chance performance 0.50 ) to 0.88 at $26^{\circ} \mathrm{C}$ (which is over $75 \%$ better than chance performance). Since caution and self-criticism demand and even augment concentration, it is plausible that lowered arousal would tend to make subjects over-confident and less cautious.

The cue utilization test was performed in the range $20-25^{\circ} \mathrm{C}$. It was performed least well at $23^{\circ} \mathrm{C}$. Unlike tasks demanding concentration, this test is adversely affected by high levels of motivation; it is performed best by subjects who are not trying very hard. The inference must be that subjects were trying their hardest at $23^{\circ} \mathrm{C}$, which coincides almost exactly with the temperature at which they were optimally comfortable, $23.8^{\circ} \mathrm{C}$. Performance improved at temperatures above and below this value as they tried less hard. Performance of similar versions of this test by 11-year-old boys was significantly improved at a constant temperature of $27^{\circ} \mathrm{C}$ in comparison with 20 or $23.5^{\circ} \mathrm{C}$ (16). In the present experiment the same effect has been demonstrated but in a more restricted temperature range.

Reading, a well-practiced activity for 17-year-olds, was unaffected by the heat. Although a temperature of $27^{\circ} \mathrm{C}$ impaired the reading speed and comprehension of 8-year-old Swedish children (8), 11-yearold English children were able to maintain performance at the same temperature at the cost of increased effort (16). The creativity test also proved insensitive to the effects of heat for 17-year-olds. Significant effects have been shown on the same test at $27^{\circ} \mathrm{C}$ for 11 -year-olds, who returned more unique answers but were less critical of their own responses (16). The remaining tests were performed in a more restricted temperature range.

Patients with known cardiac defects have been exposed to conditions 0 and 2 of the present experiment (2). The pattern of response indicated that they responded to heat stress by becoming more tense, whereas their controls and the subjects of the present experiment appear to have become more relaxed at raised temperatures up to $27^{\circ} \mathrm{C}$.
Thermal comfort is clearly a poor guide to the probable effects of heat on mental performance. Although not specifically asked in the present experiment, some of the subjects appear to have exerted the most effort at their temperature for optimum comfort, $23^{\circ} \mathrm{C}$; this was beneficial for the performance of some tasks and detrimental for others. In another experiment (10) subjects stated that they had exerted the least effort at their temperature for optimum comfort, $27^{\circ} \mathrm{C}$; this reaction adversely affected their performance of a programmed learning task. These two experiments reflect the difficulty of making subjective estimates of thermal comfort in a meaningful way when comfort is regarded as an end in itself. Instead, thermal comfort should be regarded as a byproduct of the interaction between task and environmental effects on the behavior of the subject.

It is concluded that moderate heat stress, only a few degrees centigrade above the optimum, has a marked effect on mental performance when temperatures rise slowly. Tasks demanding concentration and clear thinking are adversely affected, but memory and cue utilization can be improved by temperatures up to $26^{\circ} \mathrm{C}$, declining rapidly thereafter in the case of male subjects. In hot weather, work involving concentration should therefore be carried out early in the day. Memory and tasks requiring an increased breadth of attention can, with advantage, be postponed until the temperature has risen, provided that it does not rise above $26^{\circ} \mathrm{C}$. The positive and negative effects of these moderate levels of heat stress are likely to be greater for men than for women.

\section{ACKNOWLEDGMENTS}

This study was supported by Statens laegevidenskabelige Fond and Statens teknisk Videnskabelige Fond, Denmark, and by Statens Institut för Byggnadsforskning, Sweden.

The present report was presented at the School of Bioengineering, Thermal Physiology and Comfort held at Karpacz, Poland, 
4-7 September 1978, and tables of raw data are included in the proceedings published by the University of Wrockaw, Poland.

\section{REFERENCES}

1. AMMONS, C. H. Task for study of perceptual learning and performance variables. Percept. mot. skills 5 (1955) 11-14.

2. ANDERSEN, I., JENSEN, P. L., JUNKER, P., THOMSEN, A. and WYON, D. P. The effects of moderate heat stress on patients with ischemic heart disease. Scand. j. work environ. \& health 2 (1976) 256-272.

3. ANDERSEN, I. and LUNDQVIST, G. R. Design and performance of an environmental chamber. Int. j. biometeorol. 40 (1970) 402-405.

4. BADDELEY, A. D. A 3-min. reasoning test based on grammatical reasoning. Psychonomic sci. 10 (1968) 341-342.

5. EASTERBROOK, I. A. The effect of emotion on cue-utilization and the organization of behaviour. Psychol. rev. 66 (1959) $183-201$.

6. EYSENCK, H. J. and WILLETT, R. A. Cue-utilization as a function of drive: An experimental study. Percept. mot. skills 15 (1962) $229-230$.

7. GREEN, O. M. and SWETS, J. A. Signal detection theory and psycho-physics. Wiley, New York, NY 1966, 455 p.

8. HOLMBERG, I. and WYON, D. P. The dependence of performance in school on classroom temperature (Educational and psychol. interactions no. 31). School of Education, Malmö 1969. 20 p.

9. LANGKILDE, G., ALEXANDERSEN, K., WYON, D. P. and FANGER, P. O. Mental performance during slight cool or warm discomfort. Arch. sci. physiol. 27 (1973) $511-518$.

10. PEPLER, R. D. and WARNER, R. E. Temperature and learning: An experimental study. ASHRAE trans. 74 (1968) 211-219.

11. POULTON, E. C., HUNT, G. M., CARPENTER, A. and EDWARDS, R. S. The performance of junior hospital doctors following reduced sleep and long hours of work. Ergonomics 21 (1978) 279-295.

12. POULTON, E. C. and KERSLAKE, D. M. Initial stimulating effect of warmth upon perceptual efficiency. Aerosp. med. 36 (1965) 29-32.

13. PROVINS, K. A. Environmental heat, body temperature and behaviour: An hypothesis. Aust. j. psychol. 18 (1966) 118-129.

14. SIEGEL, S. Nonparametric statistics. McGraw-Hill, New York, NY 1956. 312 p.

15. WINER, B. J. Statistical principles in experimental design. McGraw-Hill, New York, NY 1962. 672 p.

16. WYON, D. P. The effects of moderate heat stress on the mental performance of children (National Swedish Institute for Building Research Documents 8). National Swedish Institute for Building Research, Stockholm 1969. $83 \mathrm{p}$.

17. WYON, D. P. The effects of moderate heat stress on typewriting performance. Ergonomics 17 (1974) 309-318.

18. WYON, D. P., ANDERSEN, I. and LUNDQVIST, G. R. Spontaneous magnitude estimation of thermal discomfort during changes in the ambient temperature. $J$. hyg. (London) 70 (1972) 203-221.

19. WYON, D. P. and HOLMBERG, I. Systematic observation of classroom behaviour during moderate heat stress. In: F. J. LANGDON, M. A. HUMPHREYS and J. F. NICOL (eds.), Thermal comfort and moderate heat stress, (Building research establishment report 2). Her IMajesty's Stationery Office, London 1973. 284 p. 